\title{
(c) (1) \\ Política de preservação digital: caso Pinacoteca de São Paulo
}

Charlley dos Santos Luz

Arquivista, Mestre em Ciências da Informação, Consultor e Professor.

Isabel Cristina Ayres da Silva Maringeli

Mestre em Ciência da Informação pela Escola de Comunicações e Artes da Universidade de São Paulo (2016). Especialista em Bens Culturais: Economia e Gestão pela Escola de Economia de São Paulo da Fundação Getulio Vargas (MBA EESP-FGV, 2009). Bacharel em Biblioteconomia e Documentação pela Fundação Escola de Sociologia e Política de São Paulo (FESP-SP, 1993)

http://dx.doi.org/10.1590/1981-5344/2995

Apresenta o relato de caso da estruturação e definição para implantação da Politica de Preservação Digital da Pinacoteca de São Paulo. Estabelece os principais elementos, determina o processo de diagnóstico e seus principais apontamentos. Traz a estratégia e os componentes da Política de Preservação Digital da Pinacoteca - Objetivos 2026.

Palavras-chave: Arte. Pinacoteca de São Paulo. Preservação digital. Política de preservação digital. Repositórios digitais. Estudo de caso.

\section{Digital preservation policy: case of Pinacoteca de São Paulo}

It presents the report case of structure and definition to implementation of Digital Preservation Policy of the Pinacoteca de São Paulo. Sets out the main elements, determines the process of diagnosis and your main results. Brings the strategy and the components of the Digital Preservation Policy Pinacoteca - Goals 2026. 
Keywords: Art; Pinacoteca de São Paulo; Digital preservation policy; Informational diagnosis; Digital repositories; Case study.

Recebido em 06.11.2016 Aceito em 10.10.2017

\section{A preservação digital para a Pinacoteca de São Paulo}

A preservação digital é um problema de pesquisa estudado há décadas pelo mundo acadêmico, porém pouca prática efetiva de implantação e registros de casos no Brasil. A implementação de políticas de preservação digital é muito mais uma preocupação de instituições públicas ou de grande importância para a sociedade, do que uma realidade para instituições de outros níveis e personalidades jurídicas. Em relação as instituições museológicas, a prática de estruturar arquivos vinculado às funções museológicas é mais contemporânea. A preservação digital para essas instituições, passa a ser uma necessidade a ser implantada de forma imediata.

Há uma necessidade de fixar a política de preservação digital junto ao desenvolvimento de nova mentalidade de valorização em relação ao patrimônio digital nacional. A solução, para todos os casos, é a implantação de uma política de preservação digital por meio da criação de estratégias de preservação e compromissos organizacionais.

Segundo Duranti e Preston (2008), uma política é um conjunto de regras e princípios que apoiam as tomadas de decisão e as ações em prol de um determinado aspecto objetivo de preservação. Esta política deve ser apoiada pelo nível estratégico da instituição, tecnologicamente neutra e deve dar suporte a estruturas de governança e à cultura organizacional. Serve como modelo que define os requisitos e procedimentos para prática de preservação digital, porém buscando não seria isso uma forma prescritiva.

Tendo-se em conta que é necessário o estabelecimento de políticas, diretrizes, programas e projetos específicos, legislação, metodologias, normas, padrões e protocolos que minimizem os efeitos da fragilidade e da obsolescência de hardware, software e formatos e que assegurem, ao longo do tempo, a autenticidade, a integridade, o acesso contínuo e o uso pleno da informação a todos os segmentos da sociedade brasileira (CONARQ, 2005).

\section{Contexto de custodia}

O Centro de Documentação e Memória (aqui chamado CEDOC) da Pinacoteca de São Paulo é responsável pela guarda permanente dos documentos arquivísticos produzidos e recebidos pela instituição, e por documentos de outros fundos arquivísticos relacionados ao domínio das artes. 
Nesse âmbito, o CEDOC tem por objetivo coletar, conservar, organizar, armazenar e tornar acessível ao público os documentos pertencentes aos seus arquivos e coleções. Desde sua criação, em 2005, foram descritos e organizados mais de 30.000 documentos, dentre conjuntos e itens documentais, registrados no banco de dados Automação de Bibliotecas e Centros de Documentação (ABCD).

$O$ acervo do CEDOC é formado por itens que documentam as origens, o desenvolvimento e as atividades do museu e estão organizados em três segmentos:

1) Arquivo Institucional - Fundo Pinacoteca;

2) Arquivos Privados - Fundos Pessoais e de Entidades;

3) Coleções Privadas.

O Fundo Pinacoteca inclui toda a documentação administrativa de guarda permanente produzidos pelos Núcleos pertencentes à atividademeio (Financeiro, Comunicação, Recursos Humanos, Administração Predial e Comunicação Institucional) e às atividades-fim (Educativo, Pesquisa e Curadoria, Conservação e Restauro, Núcleo de Acervo Museológico, Arquivo e Biblioteca Walter Wey). Custodia, também, a documentação produzida pela Associação Pinacoteca Arte e Cultura (APAC), incluindo a Diretoria e os Conselho de Administração e o Conselho de Orientação Artística, os registros audiovisuais de eventos realizados no museu e os registros de entrevistas e testemunhos de personalidades do mundo das artes (história oral).

Os Fundos Privados são formados por conjuntos de documentos provenientes de personalidades do mundo das artes (artistas, curadores e demais) e por Fundos de outras instituições. Este acervo se constitui em fonte fundamental de pesquisa para a história do museu e das suas coleções, para o estudo da evolução histórica das exposições e também para a construção do panorama das artes visuais no Brasil.

Nos últimos anos o CEDOC tem coletado um volume considerável de documentos nato-digitais, os quais são armazenados nas mídias enviadas pelos Núcleos produtores. Diante desse fato, em 2016 foi iniciado o Programa de Recolhimento de Documentos, que inclui, em seu escopo uma metodologia para coleta de documentos digitais. Essa medida visa, sobretudo, ao estabelecimento de um padrão para nomenclatura de documentos e para transferência direta no servidor do Centro, evitando-se assim a utilização dessas mídias de transporte que além de não serem confiáveis, são de curta durabilidade.

Além dos documentos nato-digitais, são armazenados os documentos digitalizados, como por exemplo, as plantas históricas da Pinacoteca, que estão em processo de digitalização desde 2016 . O acervo digitalizado, se por um lado traz facilidade para o acesso e contribui para a preservação do documento original, por outro lado acarreta novos desafios, dentre os quais estão as ações necessárias para preservação digital. 
Nesse contexto, é válido mencionar que diversas ações para preservação têm sido desenvolvidas pelo CEDOC, tendo em vista que o patrimônio arquivístico digital tem valor histórico para a pesquisa e para a memória. Não é possível confiar nos arquivos armazenados em CD, DVD etc., nem tampouco é possível recuperar adequadamente os arquivos que estão sendo migrados destas mídias para o Storage (servidor) da Pinacoteca de São Paulo. Algumas mídias não funcionam corretamente, ou não possuem identificação que permita a contextualização do documento dentro do Arquivo, ou seja, perderam seus metadados originais.

Os documentos de arquivo apresentam complexidades em relação a outros objetos digitais no sentido de que a perda dos metadados associados a eles implica na descontextualização dos documentos dentro do fundo de arquivo, comprometendo, desta forma a observância do Princípio de Ordem Original que "levando em conta as relações estruturais e funcionais que presidem a gênese dos arquivos, garante sua organicidade" (CAMARGO, BELLOTTO, 1996, p. 61-62).

Visando garantir a permanência e acesso às gerações futuras, para que a memória institucional seja preservada, e para que as informações produzidas durante as atividades institucionais estejam disponíveis para a pesquisa futura.

\section{0 caso Pinacoteca: um diagnóstico}

Para a Pinacoteca, foi pensado que o ponto de partida para a definição de uma política era, antes de tudo, ter uma estratégia clara. Segundo a British Library (2014) uma estratégia de preservação digital descreve uma visão, que tem princípios. Estes princípios definem o escopo das políticas e, a partir disso, criam, conforme consta da figura 1 , instrumentos para implementação dessas políticas.

Figura 1 - Estratégia de preservação digital

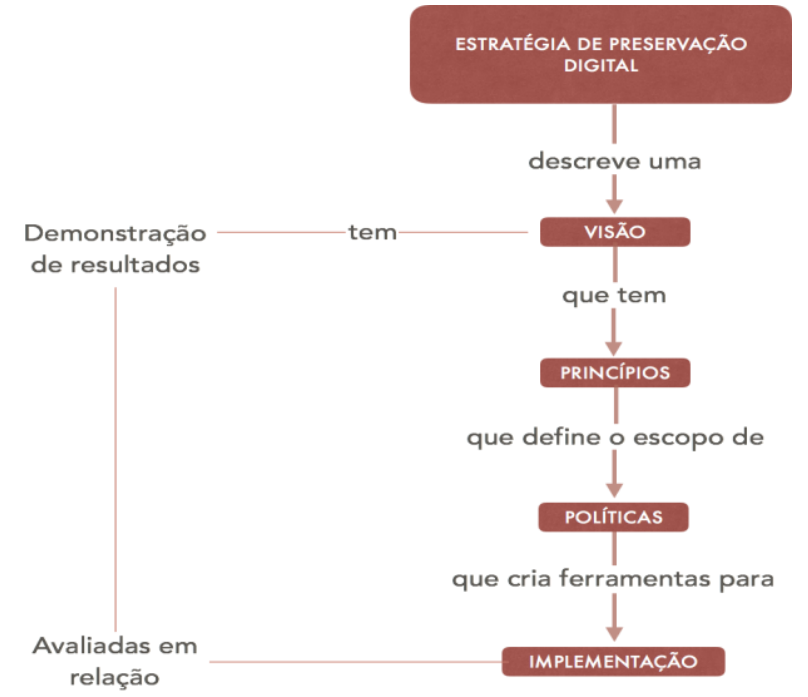

Fonte: Adaptado pelos autores a partir de British Library (2013). 
Para poder enxergar a estratégia de forma ampla foi realizado um diagnóstico com base em elementos levantados por Miguel Ângelo Márdero Arellano e consolidados por Gama Oliveira (2001) em sua tese de doutorado. Porém, como os elementos aplicados na abordagem sugerida são utilizados para coleções de bibliotecas, precisamos adaptar para ser um diagnóstico com abordagem arquivística.

Assim, ocorreu a adaptação das exigências legais da preservação, pois, por exemplo, uma coleção tem que atender à lei do depósito legal, enquanto que um repositório arquivístico precisa atender à Lei de Acesso à Informação (se for da área pública). Estes elementos adaptados de Gama (2001) foram agrupados em 11 grupos de abordagem do diagnóstico. Estes grupos eram os seguintes:

1 - critério para seleção do patrimônio digital; 2 - depósito de documentos amparado pela lei de acesso à informação; 3 - uso de padrões e protocolos abertos; 4 - padronização de estratégias de preservação; 5 - padronização de meta dados de preservação de acordo com padrões pré-estabelecidos; 6 - adoção de padrões na criação, armazenamento e transmissão de documentos digitais; 7 - aplicação de técnicas de preservação digital respeitando as especificidades de cada problema; 8 - uso de instrumentos oriundos de ti e que garantem integridade, confiabilidade e autenticidade dos documentos digitais; 9 legislação que garantem a proteção do patrimônio digital e o seu reconhecimento pleno com o valor de prova;10-gerenciamento de um planejamento a longo prazo; 11 - alinhamento a agenda nacional de pesquisa em relação aos problemas de preservação e acesso e longevidade digital; monitoramento do surgimento de novos padrões; pesquisa e desenvolvimento de soluções abertas em cooperação com TI (Tecnologia da Informação).

Este diagnóstico possibilitou um retrato da situação de preservação digital atual na instituição. Foi possível mapear boas práticas já realizadas pelos setores em seus arquivos correntes, o que facilita para o processo de recolhimento dos documentos digitais arquivísticos. Através do diagnóstico foi possível verificar o processo de seleção para a guarda permanente dos documentos gerados pela instituição, a situação dos suportes e a situação das coleções existentes nas áreas fim da instituição.

Com a revisão dos instrumentos já existentes utilizados na gestão documental foi possível verificar a necessidade de atualização de determinados regulamentos, além de potencializar a revisão de projetos que já estejam correndo, como por exemplo, a atualização do quadro de arranjo do arquivo permanente que está ocorrendo em 2016.

Em relação à própria estrutura da instituição como um arquivo permanente, foi possível verificar as normas que devem ser seguidas e aplicadas pela instituição em relação ao acesso à informação, a gestão documental, e a preservação de patrimônio cultural. Por meio do diagnóstico, ainda foi possível verificar a situação dos padrões de arquivos utilizados, os bancos de dados dispersos localizados nas áreas de negócio e a forma como são utilizados pelos usuários que geram os documentos. 
Além disso, o processo de diagnóstico também mostrou a realidade dos acervos que necessariamente não são arquivísticos, porém que compõem o patrimônio da instituição. Parte desse acervo já está em formato digital, estamos falando de obras de Arte Contemporânea que usam elementos eletrônicos e digitais em sua composição. A verificação das estratégias implementadas foram ideais, pois assim foi possível verificar o que já tem sido feito para que seja potencializado as boas práticas existentes.

A relação com as tecnologias da informação disponíveis também foi verificada por meio do diagnóstico, evidenciando-se a estrutura existente em relação a utilização de recursos de TI e que apoiam a autenticidade documental.

Como resultado do diagnóstico, foram elaboradas estratégias estruturais e operacionais (MÁRDERO ARELLANO, 2004). Nas estratégias operacionais foram definidos os padrões a serem adotados de forma macro na estratégia e na política de preservação digital, além da definição de metadados de preservação digital e montagem de infraestrutura. Faz parte da estratégia principal para a instituição, estabelecido a partir de então, o uso de um repositório digital confiável arquivístico (RDC-Arq).

\section{Opções estratégicas}

Conforme Márdero Arellano (2008, p. 10), "uma política aceitável de preservação digital implica em observar e aplicar procedimentos que podem ser aceitos, inclusive, como estratégias de preservação". Para o autor, essas estratégias são relativas a tecnologia de informação, no que for tocante a hardware e software de migração de dados, emulação tecnológica e espelhamento de dados.

Outros itens importantes referenciam a necessidade de integridade do conteúdo a ser preservado, além dos custos envolvidos, o que impacta, portanto, na política de seleção do que será preservado.

As estratégias deveriam estar fundamentadas nos seguintes pontos:

a) políticas e normas corporativas de gestão de documentos;

b) planos estratégicos de preservação;

c) ambiente tecnológico específico (sistema e repositório).

Além disso, a abordagem de que os métodos recomendados para preservação dos objetos digitais poderiam ser organizados em dois tipos: os estruturais e os operacionais. Por último, os objetivos da política de preservação digital foram estabelecidos como da preservação da informação histórica da Pinacoteca para benefício das futuras gerações até o monitoramento e avaliação de riscos inerentes a geração em custódia de documento serviços digitais.

\section{A política de preservação digital}


Para estabelecer a política de preservação digital, além de deixar clara a estratégia por meio dos objetivos, foram declarados os documentos candidatos à preservação digital. Esta foi uma espécie de filtro que define os requisitos para os documentos digitais serem considerados de interesse arquivístico. Estes requisitos são os que dão característica aos documentos arquivísticos atuais: originalidade; autenticidade; integridade; usabilidade (e representatividade, interpretabilidade); condições de arranjo (deve ser avaliado como documento permanente).

O diagnóstico também estabeleceu a avaliação dos riscos ao patrimônio digital. E tem destacado como importante no modelo estabelecido pela Northeast Document Conservation Center (NEDCC, s.p.). Esta avaliação pode indicar elementos que devem ser trabalhados pelo período de 10 anos de implementação da política de preservação digital da Pinacoteca. Assim estabelecemos um quadro com os itens diagnosticados. E sua situação em 2016, eram 16 itens que devem ser trabalhados como forma de implementação da estratégia e da política de preservação digital.

A Política é composta de 14 partes que estabelecem:

1) Contexto normativo: as regras e leis que devem ser observadas e seguidas pela instituição de forma a ficar dentro da lei;

2) Escopo da Política de Preservação Digital: estabelece as grandes estratégias a serem implantadas pela Política de forma a se desdobrar em projetos e Objetivos 2026;

3) Documentos candidatos à Preservação Digital: estabelece claramente os requisitos para o documento ser preservado;

4) Avaliação dos Riscos ao Patrimônio Digital: com base no diagnóstico, elege pontos de atenção a serem corrigidos com os Objetivos 2026.

5) Declaração de Interesses: define os Projetos e metodologias a empreender, originados da política;

6) Compromissos organizacionais: estabelece os métodos práticos de gestão visando a preservação digital permanente;

7) Objetivos 2026: definem objetivos a serem trabalhados a longo prazo, e com previsão de realização de até dez anos;

8) Preservação e Controle de Qualidade: estabelece marcos gerais de manutenção da qualidade arquivística, tanto para documentos digitalizados quanto para documentos nato digitais;

9) Gestão de Metadados: define como os metadados deverão ser aplicados para garantirem a autenticidade e reportarem o contexto de criação dos documentos digitais; 
10) Gestão de Correio Eletrônico: determina como os e-mails serão tratados com documentos arquivísticos;

11) Governança: Papéis e Responsabilidades, o Modelo da Governança e os Processos da Política de Preservação Digital;

12) Formação continuada: estabelece o papel de incentivador do tema Preservação Digital e a busca pelo desenvolvimento de competências próprias de da comunidade.

A política, ao determinar uma declaração de interesses, define como a Pinacoteca faz para almejar a preservação digital de seus documentos, para garantir o acesso a longo prazo dos fundos e coleções. Neste ponto a política de preservação digital estabeleceu, portanto, projetos que devem ser empreendidos.

Os projetos e metodologias a empreender originados da política são como o da revisão do quadro de arranjo, do processo de recolhimento metodológico com períodos de prazos definidos para gestão corrente de documentos, criação de métodos para inserção de metodologia preconizada pelo OAIS, no processo de recolhimento e tratamento de acervo permanente. Além disso, a Pinacoteca declara ter interesse de ser participante de rede que estimule intercâmbio e difusão de documentos digitais de museus e Centro de Documentação destas instituições.

A implantação de um repositório digital confiável arquivístico é declarado como necessário para gerenciar o modelo proposto de pacotes informacionais e que esteja aderente a evolução de formatos, para garantir o acesso a longo prazo. A implantação de metadados sugeridos e definidos também faz parte da declaração de interesses da política de preservação digital.

Além de declarar os projetos a serem empreendidos são declarados compromissos organizacionais em relação ao processo de preservação digital. A política declara como estratégia principal de preservação o princípio de migração. Este princípio deve estar ancorado em normas e modelos como o OAIS, além disso, a aplicação deve ter independência de arquivamento, ou seja, o repositório deverá ser utilizado somente para guarda de documentos arquivísticos, de forma a manter a sua integridade ou por meio de tecnologia que propicie o isolamento deste repositório, como os pipelines do Archivemática.

A eliminação de mídias também é declarada na política, possibilitando que após a ingestão ou admissão do documento no ambiente do repositório as mídias que ele faz parte podem ser eliminadas com o aval da CADA (Comissão de Avaliação Documental e Acesso). Esses compromissos práticos ainda foram desdobrados nos seguintes pontos de compromisso: arranjo do acervo, formato de documento, digitalização, padronização de metadados, repositório digital governança da política de preservação e rede com centros de documentação similares. 
A política ainda traz os Objetivos 2026. O quadro com os itens diagnosticados e a situação em 2016 projeta a meta final para o ano de 2026. Assim, a instituição sugere que nesses próximos 10 anos sejam priorizados esses objetivos delimitando assim ações a longo prazo para preservação de seu patrimônio documental. Trata, ainda, de temas como a interoperabilidade, o sistema de difusão, o armazenamento, uso de identificador universal para documentos, backups, metadados, presunção de autenticidade, segurança da informação e repositório digital.

A política, por final, ainda estabelece processos para preservação e controle de qualidade. São determinados os padrões de digitalização que o CEDOC deverá aplicar aos documentos com vistas à preservação a longo prazo e acesso a este patrimônio documental. As regras aplicadas tratam de como deve ocorrer a digitalização, determinando a resolução, os formatos e a forma básica de indexação. Além disso, com base no modelo OAIS, são estabelecidos os formatos para preservação e para difusão, estabelecendo um quadro de migração para vários gêneros documentais desde áudio, passando pelo e-mail até vídeos e arquivos de texto.

\section{Gestão de metadados}

A gestão de metadados é um capítulo especial da Política de Preservação da Pinacoteca - Objetivos 2026. Os metadados devem estar codificados em estruturas padronizadas de descrição, o que gera ao CEDOC a determinação de estabelecer processos descritivos de seu acervo. O CEDOC estabelece a norma internacional Internacional Standard of Archival Description-General (ISAD-G) como o seu padrão descritivo. A aplicação desses elementos na etapa de descrição deverá acompanhar os metadados a serem aplicados nos documentos digitais. Para os casos de documentos gerados na rede interna da Pinacoteca, são estabelecidos os elementos básicos para manutenção do contexto de geração informacional.

\section{Gestão de correio eletrônico}

Conforme estabelecido na Política, as mensagens de correio eletrônico são documentos arquivísticos ao auxiliarem as atividades e o processo de tomada de decisão. Tal como fornecer evidencia em caso de litigio, além de proteger os interesses da Pinacoteca e os direitos dos funcionários e dos usuários. Além disso, os e-mails podem ser considerados documentos arquivísticos se assegurarem as atividades de pesquisa, desenvolvimento e inovação, além de manterem a memoria corporativa coletiva.

As mensagens de correio eletrônico corporativo também são considerados os documentos nato digitais, e são objeto de atenção da política de preservação digital. A política estabelece que o correio eletrônico deve ser declarado documento por seus autores, e portanto deve compor dossiês e séries documentais que serão recolhidas futuramente pelo CEDOC. 


\section{Governança, os papéis e responsabilidades}

A política de preservação da Pinacoteca estabeleceu, além de elementos estruturais e operacionais para a implementação da política, o processo de governança e acompanhamento da implantação dos Objetivos 2026. A governança é adaptado de Heritage ${ }^{1}$ que estabelece formas para a Responsabilidade Administrativa e a Viabilidade organizacional na execução de uma Política de Preservação Digital.

Para a política de preservação da Pinacoteca foi criado um comitê institucional, que é composto por uma área estratégica e uma área tática. Este comitê será composto pelos principais núcleos da instituição, além de membro da diretoria da pesquisa e curadoria. A governança foi estruturada pela própria política, sendo essa responsável por aprovar planos específicos de implementação de soluções que almejem os Objetivos 2026 da Pinacoteca, acompanhamento da produção e qualidade da governança tática e encaminhamentos operacionais do CEDOC, definição das estratégias de comunicação interna e dos conteúdos a serem transmitidos às equipes. Este comitê também fará análise dos relatórios de planos específicos e daí evolução dos objetivos para 2026. A princípio o comitê deverá se reunir semestralmente.

Como parte final da política é declarada a importância da formação continuada das equipes internas da Pinacoteca para evolução, implantação e manutenção da política de preservação digital. A coordenação do CEDOC deverá encaminhar formas de manter pesquisa, estudo contínuo sobre soluções e quantas novas estratégias de preservação digital, novos formatos, normas e padrões que possam ser desenvolvidas em cooperação e implantadas visando a melhoria da preservação digital a longo prazo da instituição.

\section{Considerações finais}

A política de preservação da Pinacoteca serve para garantir a integridade e autenticidade dos documentos sob sua custódia. Para tanto, são seguidos princípios arquivísticos apoiados em tecnologias da informação que impulsionem a manutenção e a presunção de autenticidade.

A política possibilitou, portanto, após avaliar os riscos ao patrimônio digital da instituição, a oportunidade de fazer uma declaração de interesses e estabelecer compromissos organizacionais e objetivos que devem ser cumpridos até 2026. Estabelece, para tanto, formas de controle da qualidade, gestão de metadados e do correio eletrônico, governança e formação continuada.

Ela possui elementos como declaração de princípios, ligações contextuais, objetivos declarados e claros de preservação, responsabilidade nos procedimentos, orientação e implementação. Ao definir as estratégias de preservação, identificou as partes envolvidas na

${ }^{1}$ Disponível em: <https://www.canada.ca/en/heritage-information-network/services/digital-preservation/policyframework-development-guideline.html>. Acesso em: 13 out. 2016. 
política nos procedimentos para sua implementação, assim sendo possível estabelecer procedimentos para implementação de ações de preservação do patrimônio documental digital da Pinacoteca de São Paulo.

Tal experiência foi importante por traduzir o anseio da instituição na preservação da história da memória da Arte de São Paulo e do Brasil, e também dar condições para a confiabilidade nos documentos sob sua custódia.

A Carta da Unesco (2003) é uma das referências que fundamentaram a elaboração desta política. Ela acrescenta as características que apoiam a preservação digital, como os termos de responsabilidade, a viabilidade, a sustentabilidade, adequação técnica, segurança e responsabilização de procedimentos, todos atendidos pela Política de Preservação Digital da Pinacoteca. A preservação digital passou a ser uma preocupação maior no Brasil após a Lei 12.527 de 2011, que estabelece o direito de acesso dos cidadãos as informações públicas.

A implementação, em 2016, da política de preservação digital da Pinacoteca mostra um caminho a ser percorrido pela instituição na garantia do acesso futuro à sua história. Uma política de preservação digital serve como orientação para gestão da preservação e para o acesso aos objetos digitais produzidos pela instituição. Além disso, procuramos também destacar a importância da autenticidade documental, pois tratase de um acervo arquivístico. Porém a Pinacoteca terá os próximos 10 anos para garantir a história que está sendo escrita hoje para o futuro.

\section{Referências}

THE BRITISH LIBRARY. Digital preservation. 2013. Disponível em: http://www.bl.uk/aboutus/stratpolprog/collectioncare/digitalpreservation/ Acesso em: 20 out. 2016.

CAMARGO, A. M. de A.; BELLOTTO, H. L. (Coord.). Dicionário de terminologia arquivística. São Paulo: Associação dos Arquivistas Brasileiros; Núcleo Regional de São Paulo; Secretaria de Estado da Cultura, 1996.

CONSELHO NACIONAL DE ARQUIVOS (CONARQ). Carta para a preservação do patrimônio arquivístico digital. 2005. Disponível em: <http://www.conarq.arquivonacional.gov.br /media/carta.pdf >. Acesso em: 28 out. 2016.

DURANTI, L.; PRESTON, R. International research on permanent authentic records in electronic systems (InterPARES) 2: experiential, interactive and dynamic records. CLEUP, 2008. Acesso em: 13 out. 2016.

GAMA, I. de O. Elementos para proposta de uma política de preservação digital: o caso das bibliotecas digitais da área de música. 2010. $83 \mathrm{f}$ Monografia (Graduação em Biblioteconomia) - Universidade Federal do Estado do Rio de Janeiro, Rio de Janeiro, 2010. Disponível em: <http://eprints.rclis.org/14422/>. Acesso em: 29 set. 2016. 
GOVERNMENT OF CANADA. Digital preservation policy framework: development guideline Version 2.1. 2016. Disponível em $<$ https://www.canada.ca/en/heritage-informationnetwork/services/digital-preservation/policy-framework-developmentguideline.html>. Acesso em: 13 out. 2016.

mÁRDERo ARELlano, M. A. Preservation of digital documents. Ciência da Informação, v. 33, n. 2, p. 15-27, 2004.

MÁRDERO ARELLANO, M. A. Critérios para a preservação digital da informação científica. 354f. Tese (Doutorado em Ciência da Informação) Departamento de Ciência da Informação, Universidade Federal de Brasília, Brasília, 2008.

NORTHEAST DOCUMENT CONSERVATION CENTER (NEDCC). Digital
preservation policy template. [20--?]. <https://www.nedcc.org/assets/media/documents/SoDAExerciseToolkit.p df>. Acesso em: 29 set. 2016.

ORGANIZAÇÃO DAS NAÇÕES UNIDAS PARA A EDUCAÇÃO, A CIÊNCIA E A CULTURA (UNESCO). Carta para la preservación del patrimonio digital. 2003. em: <http://www.unesco.org/new/fileadmin/MULTIMEDIA/HQ/CI/CI/pdf/mow/ charter_preservation_digital_heritage_es.pdf>. Acesso em: 20 set. 2016. 